\title{
Identificação de impactos ambientais associados à antropização das praias do Poço e Camboinha do munícipio de Cabedelo - PB
}

\author{
Identification of environmental impacts associated with the anthropization of the Poço and \\ Camboinha beaches, Cabedelo - PB
}

AGRÍCIO ${ }^{1}$, A. M.S.

a.d.i.e.l@hotmail.com

\begin{abstract}
Resumo
Este trabalho objetiva caracterizar as condições ambientais e os impactos decorrente da erosão costeiras nas praias do Poço e Camboinha, no munícipio de Cabedelo, Paraíba. As praias supracitadas foram escolhidas como objetos de análise geográfica desta pesquisa em função de comporem uma área diagnosticada com intensa atividade erosiva. O principal motivo dessa erosão decore da predominância das residências em áreas de ambiente praial, em terrenos pertencentes à União, portanto, estão mais próximas ao mar do que deveriam e, consequentemente, são atingidas por ondas fortes durante as marés altas. A metodologia utilizada para composição do diagnóstico se baseia em listagem de controle de campo (check-list), aplicados em pontos demarcados em cada uma das praias, além de registros fotográficos e levantamento bibliográfico acerca da temática. Nos resultados obtidos, conferiu-se que a zona costeira estudada apresenta, em sua totalidade, ocupação por urbanização e atividades turísticas. Diante do que foi exposto, constata-se que as praias do Poço e Camboinha apresentam vulnerabilidade média à alta. $\mathrm{O}$ problema de erosão que ocorre neste trecho do litoral aponta para o avanço da ocupação sobre o ambiente praial.
\end{abstract}

Palavras-chave: Vulnerabilidade, erosão costeira, processos antrópicos.

\begin{abstract}
This study analyzes the Geo-Environmental conditions and impacts occurred in Poço and Camboinha beaches, in Cabedelo, Paraíba. It has intended to define the nature and magnitude of natural and anthropogenic processes condicionates the coastal erosion process. The selection of these areas for the execution of the research took place in the same areas that have been diagnosed with severe erosive activity, the primary reason for this erosion is in result of most houses are on beach environment areas, on State-Owned lands, are nearest the sea than they should and therefore are hit by strong waves at high tide. The methodology used for diagnostic composition is being made through field control list (check-list), applied at marked points in each of the beaches, photographic records, among other activities. The results obtained, given that, the coastal area has studied in its entirety, occupation by urbanization and tourist activity. Given what was stated it was found that the beaches of Poço and Camboinha are "medium to high vulnerability". The erosion problem that occurs in this stretch of coast points to the advancement of the occupation on the beach environment.
\end{abstract}

Keywords: Vulnerability, coastal erosion, anthropic processes.

\section{INTRODUÇÃO}

As planícies litorâneas são um dos ecossistemas com maior instabilidade inerente que se tem conhecimento e exercem um imenso fascínio sobre as populações humanas que tendem a aumentar a ocupação desse trecho territorial e suas adjacências, ainda que de modo sazonal.

Quando a ocupação torna-se intensa, os fatores antrópicos superpõem-se aos fenômenos dinâmicos, exacerbando as suscetibilidades naturais e introduzindo suscetibilidades induzidas e criando situações de crises cada vez mais complexas de diversos tipos (SUGUIO, 2000).

Devido a essa intensa ocupação do litoral brasileiro e sua vasta extensão territorial, o nível de preocupação em se planejar racionalmente as intervenções humanas vem crescendo. Porém, 
esbarra na falta de dados pretéritos, de profissionais qualificados e de recursos governamentais, o que acaba gerando sérios problemas de ordem física e biológica nos mais variados ambientes costeiros tais como: praias, manguezais, estuários, falésias, dunas e tabuleiros litorâneos.

Em virtude da complexidade natural e do nível de intervenção humana na organização do espaço geográfico do ambiente costeiro, esse segmento do relevo vem merecendo atenção cada vez maior quanto à manutenção do seu equilíbrio, o que acaba levando à necessidade de um conhecimento detalhado de suas estruturas e das forças que intervêm no ajustamento de suas formas (FEITOSA, 1996).

Fazendo um comparativo populacional entre os dados do IBGE nos censos de 2000 e 2010, podemos perceber que o litoral paraibano é caracterizado pela grande densidade populacional no núcleo da região metropolitana de João Pessoa, com grande crescimento em seu entorno. Os municípios que compõem essa região são: Alhandra, Bayeux, Caaporã, Cabedelo, Conde, Cruz do Espirito Santo, João Pessoa, Lucena, Pedra de Fogo, Pitimbu, Rio Tinto e Santa Rita.

O município de Cabedelo está inserido em uma unidade geomorfológica identificada como planície costeira, com altimetria que varia de 0 a 10 metros. O relevo do município, de origem quaternária, é marcado pela ocorrência de terraços, praias, recifes, restingas, e cordões litorâneos, posto que a sua formação é resultante da ação de elementos marinhos e flúvio-marinhos. Sendo assim, as atividades que se desenvolvem no município têm ligação direta com as características litorâneas do mesmo.

O processo de ocupação e uso da faixa costeira do município de Cabedelo vem sofrendo, nos últimos anos, uma ação antrópica caracterizada por processos acelerados de urbanização, industrialização, uso turístico e portuário (Plano de Gestão ambiental para o Município de Cabedelo - GERCO/SUDEMA, 1996).

O objetivo primordial dessa pesquisa é analisar as condições ambientais e os impactos erosivos ocorridos nas praias do Poço e Camboinha, decorrentes da ação antrópica e das condições ambientais, de maneira a gerar um material que proporcione uma gestão costeira adequada.

A área de estudo compreende as praias do Poço e Camboinha. A praia do Poço faz limite com a praia de Ponta de Campina ao sul, a praia de Camboinha ao norte, Oceano Atlântico ao leste e ao oeste faz limite com a $\mathrm{Br}$ 230. Já a praia de Camboinha faz limite com a praia do Poço ao sul, a praia de Areia Dourada ao norte, Oceano Atlântico ao leste e ao oeste com a Br 230.

\section{METODOLOGIA}

Realizou-se, como ponto de partida, um levantamento bibliográfico acerca da temática, que juntamente ao conhecimento adquirido no Projeto de Pesquisa (PIVIC) intitulado "Caracterização 
morfodinâmica e geoambiental das praias do Poço e Camboinha do município de Cabedelo - PB", que teve vigência entre os anos de 2013 e 2014, serviu de suporte para a realização da pesquisa e para a escolha do local de estudo, que foi selecionado por observações do uso e ocupação da porção litorânea.

Para caracterizar a área de estudo, foi sugerido o método de pesquisa criado pelo projeto Erosion, nos Estados Unidos em 1975, recomendados para esse tipo de estudo, que é o método de listagem de controle de campo (check-list), para identificação de impactos ambientais. Nesta pesquisa foram considerados e analisados os impactos ambientais, relacionados aos processos erosivos ocasionados pela ação antrópica decorrente do avanço irregular dos imóveis que se encontravam entre a pós-praia e o estirâncio.

O check-list consiste em uma lista de itens a serem preenchidos no campo que contribuem para a caracterização e identificação dos processos erosivos costeiros. A utilidade maior dessa metodologia é seguir um padrão de organização em todos os pontos para gerar um trabalho de alto nível.

Para identificar os processos erosivos na praia, foi utilizado o modelo do checklist proposto por Scudelari (2005), mas adaptado às feições existentes na área de estudo, ou seja, sem falésias. O modelo foi utilizado durante a segunda visita de campo realizada no dia 28 de Julho de 2016, e é composto basicamente por duas partes: a primeira refere-se à localização da área, com informações sobre: a data e horário da inspeção de campo, bem como os níveis da maré e as fases da lua; e as características do trecho, como tipos de matérias que compõem a praia, tamanho dos sedimentos, uso da faixa de praias, presença de vegetação. A segunda parte corresponde à identificação dos processos erosivos, por meio de informações como: se há faixa de praia na maré cheia, se os moradores estão sendo afetados e se há presença de aparelho de proteção/contenção na praia (murros, barreiras de rochas, telas com rochas).

Nos trabalhos em campo foram realizadas duas visitas. A primeira visita no dia 04 de julho de 2016, data escolhida por apresentar a maré de sizígia, utilizando a Tábua de Marés da DHN referente ao Porto de Cabedelo (Paraíba), fundamental para o reconhecimento das formas existentes no local, visualização da faixa de praia e escolha dos pontos de aplicação do check-lists. A segunda visita foi no dia 28 de julho de 2016; neste dia foram aplicados vários check-lists em diversos setores, que apresentavam ausência ou presença de erosão. Formou-se, a partir disso, um mapa que realiza a classificação dos trechos da praia em três tipos, sem indícios de erosão, processos erosivos que não atingem imóveis, processos erosivos que atingem imóveis (causam danos). Foram feitos registros fotográficos e anotações relevantes. 


\section{RESULTADOS E DISCUSSÃO}

\section{1 - CARACTERIZAÇÃO GEOLÓGICA E GEOMORFOLÓGICA}

A geologia da área, segundo Falcão (2004), é predominantemente sedimentar, representada por depósitos que vão do cretáceo ao holoceno. Os sedimentos quaternários são predominantes e constituem toda a área da planície de Cabedelo que é denominada ao sul e sudeste pelos depósitos plio-pleistocênicos da Formação Barreira que serviram de apoio ao desenvolvimento da restinga. $\mathrm{O}$ assoalho onde se depositam os sedimentos quaternários é representado pelas rochas cretáceas do grupo Paraíba: calcários de Formação Gramame e arenitos da Formação Beberibe. Desta, só os calcários afloram a sudoeste da área e são explorados economicamente desde tempos mais remotos.

A origem da restinga de cabedelo está vinculada aos processos erosivos da formação Barreiras associado às variações relativas do nível do mar durante o quaternário. Os sedimentos quaternários, presentes na área, caracterizam-se por apresentarem mudanças faciológicas resultantes das oscilações do nível do mar, responsáveis pela sedimentação de ambiente marinho durante as transgressões e regressões pleistocênicas e holocênicas. Eles englobam: aluviões, areias dunares e sedimentos de praia, depósitos flúvio-marinhos e estuários, arrecifes e recifes coralígenos (FALCÃO, 2004).

\section{2 - CARACTERIZAÇÃO DO AMBIENTE PRAIAL}

O ambiente praial vai além do termo praia; compreende pontos submersos, localizados além da zona de rebentação, onde as ondas de maior altura já não selecionam nem mobilizam, até a faixa de dunas e/ou escarpas que ficam à retaguarda do ambiente (REIS, 2008).

As praias são usualmente definidas como uma acumulação de sedimentos inconsolidados (areia, cascalho, argila, silte) que se estende da linha d'água na maré baixa média até uma mudança fisiográfica, tal como o declive da praia ou campos de dunas. Sendo o produto final da interação do sedimento com processos físicos como ondas, correntes e marés (KOMAR, 1998 apud Pedruzzi, 2005).

Na Figura 01 apresentam-se as feições morfológicas do ambiente praial, divididas em: antepraia (shoreface), estirâncio (foreshare) e pós-praia (backshore). 


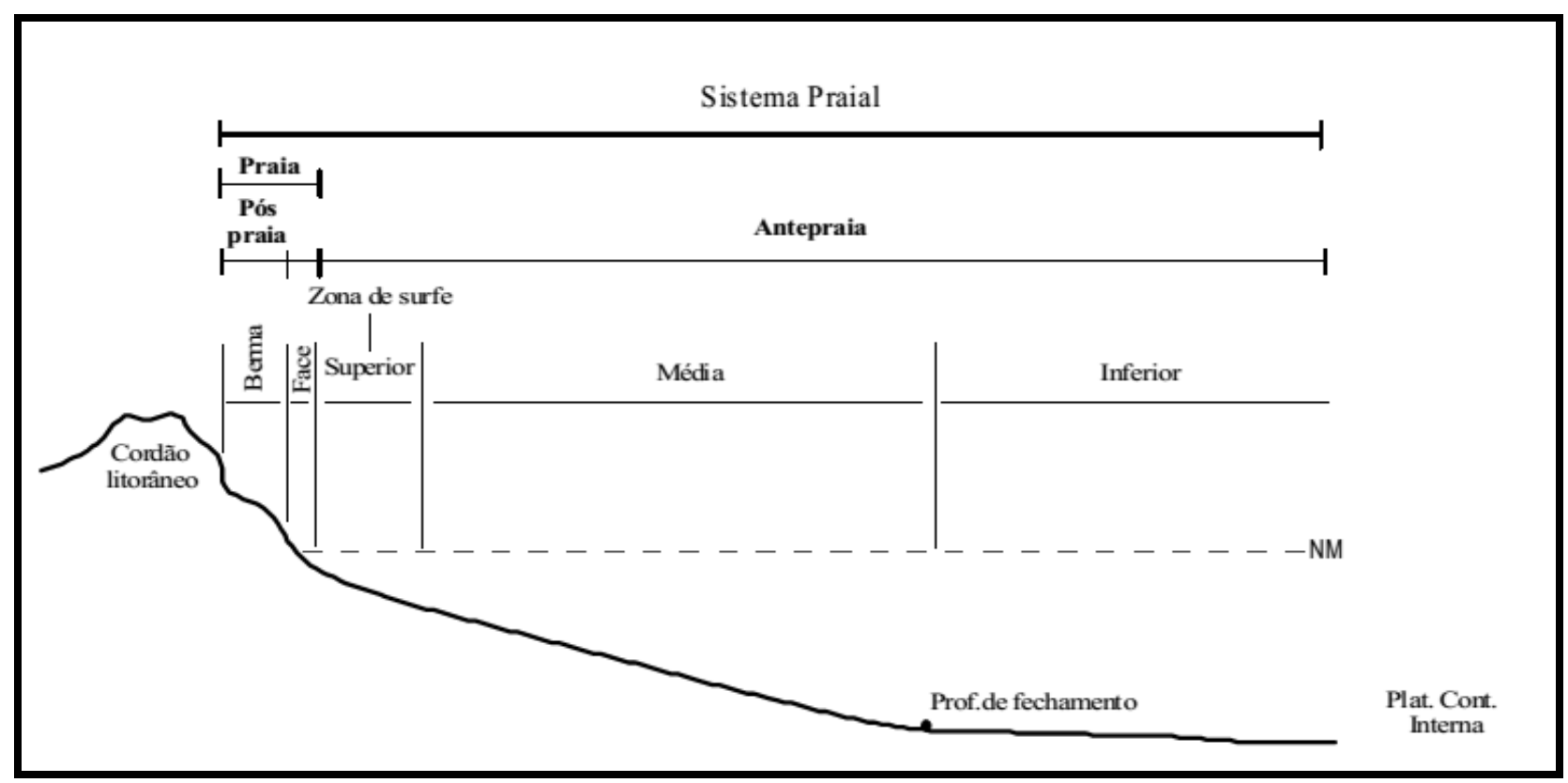

Figura 01: Feições morfológicas do ambiente praial. Fonte: Muehe (2001).

A região de antepraia se localiza entre a plataforma continental interna e a praia, caracterizando-se por um contínuo incremento do gradiente topográfico em direção ao litoral. Limita-se em direção a costa com o estirâncio, e em direção ao mar, com a zona de transição.

A região de estirâncio pode apresentar uma variedade de configurações. Sendo caracterizada pela zona entremarés, limitada pela altura mínima de maré baixa e máxima da maré alta.

A região pós-praia localiza-se fora do alcance das ondas e das marés normais, e somente é alcançada pela água quando ocorrem marés muito altas ou tempestades. Segundo Castro (1992), Nesta região formam-se terraços denominados bermas, que apresentam uma seção transversal triangular, com a superfície de topo horizontal ou em suave mergulho em direção ao continente e à superfície frontal com mergulho acentuado em direção ao mar.

\section{2 - DESCRIÇÕES DOS DADOS LEVANTADOS (CHECK-LIST).}

O método de listagem de controle de campo (check-list), foi aplicado nas duas praias, Poço e Camboinha, em vários pontos previamente analisados, onde fossem encontrados indícios de erosão, com baixa ou alta magnitude ou sua ausência.

\subsubsection{Praia do Poço}

Em todo o litoral de Cabedelo, que compreende uma área de $15 \mathrm{~km}$, a praia do Poço é a mais afetada com a ocupação desordenada de bares e residências localizados na pós-praia e no estirâncio (que se caracteriza pela zona entre marés). Em grande parte da praia, durante as marés alta, as atividades recreativas são prejudicadas pelo fato da quase inexistir faixa de praia. 
Por ser a praia que apresenta mais problemas relacionados à erosão costeira, podemos analisar na Figura 02, abaixo, que quase toda a faixa da praia do Poço demonstra um índice erosivo, representado pelos setores amarelo e vermelho demonstrados na figura. $\mathrm{O}$ setor amarelo demonstra os locais onde os processos erosivos de punho costeiro são marcantes, entretanto, não atingem imóveis nem trazem prejuízos financeiros aos moradores. Já o setor vermelho representa os locais em que os processos erosivos se apresentam de forma mais severa, onde ocorrem colisões das ondas do mar com os muros dos imóveis; nele, encontram-se evidências de muros recém-reformados, de rachaduras e até mesmo de destroços de antigas construções aniquiladas em decorrência da ação do mar.

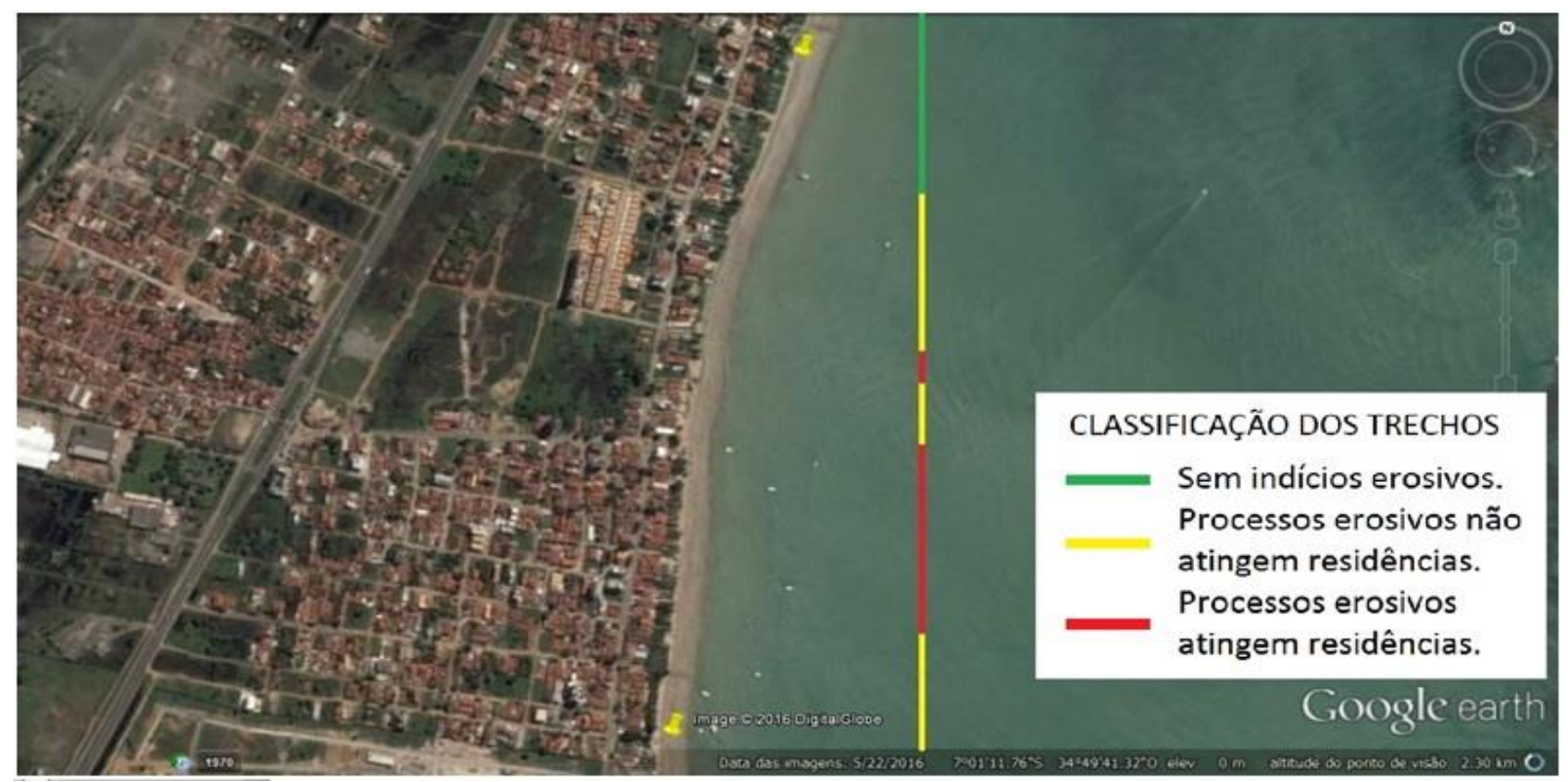

Figura 02: Praia do Poço. Fonte: Google Earth.

Os moradores, com receio de que o mar avance até seus imóveis, se organizaram para elaborar uma forma de obra de contenção que atue de maneira a abrandar a energia das ondas. Nelas, são empregados sacos de areia, muros de arrimo, telas com rochas, madeira e uma grande quantidade de rochas soltas na faixa da praia, que ocupam uma extensão de até 5 metros de largura por 2 metros de altura, como podem observar na Figura 03, abaixo: 

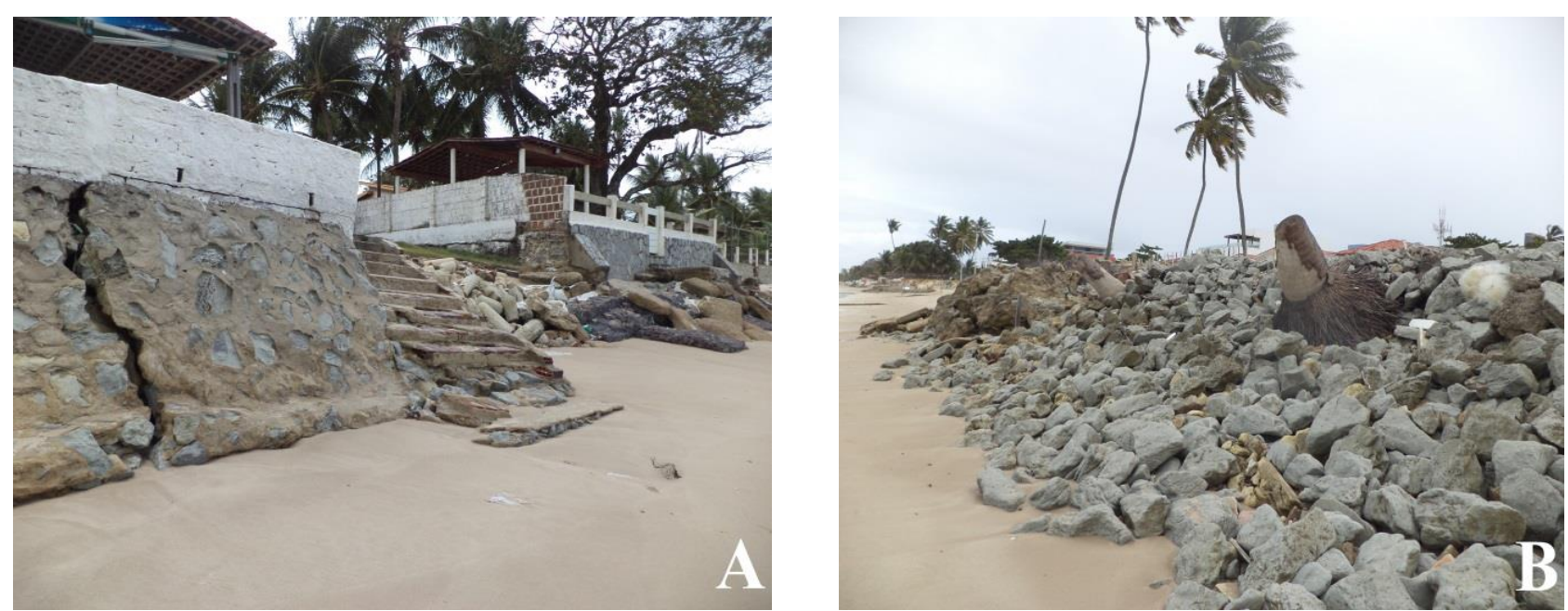

Figura 03: A - Muro de estabelecimento comercial rachado e obras de contenção ao fundo (sacos de areia, blocos de concreto); B - Rochas jogadas na praia para diminuir a energia das ondas. Fonte: Autor, Julho de 2016.

\subsubsection{Praia de Camboinha}

No Litoral de Cabedelo, existe as praias de Camboinha I, Camboinha II e Camboinha III, mas para simplificar o estudo iremos considerar como uma única praia, que designamos simplesmente de praia de Camboinha.

Na praia de Camboinha, como podemos observar na Figura 04, quase toda a sua faixa costeira faz parte da categorização verde, que são os locais onde não há processos erosivos. A ausência de processos erosivos decorre da presença de vegetação nativa (indício de estabilidade) próxima ao estirâncio.

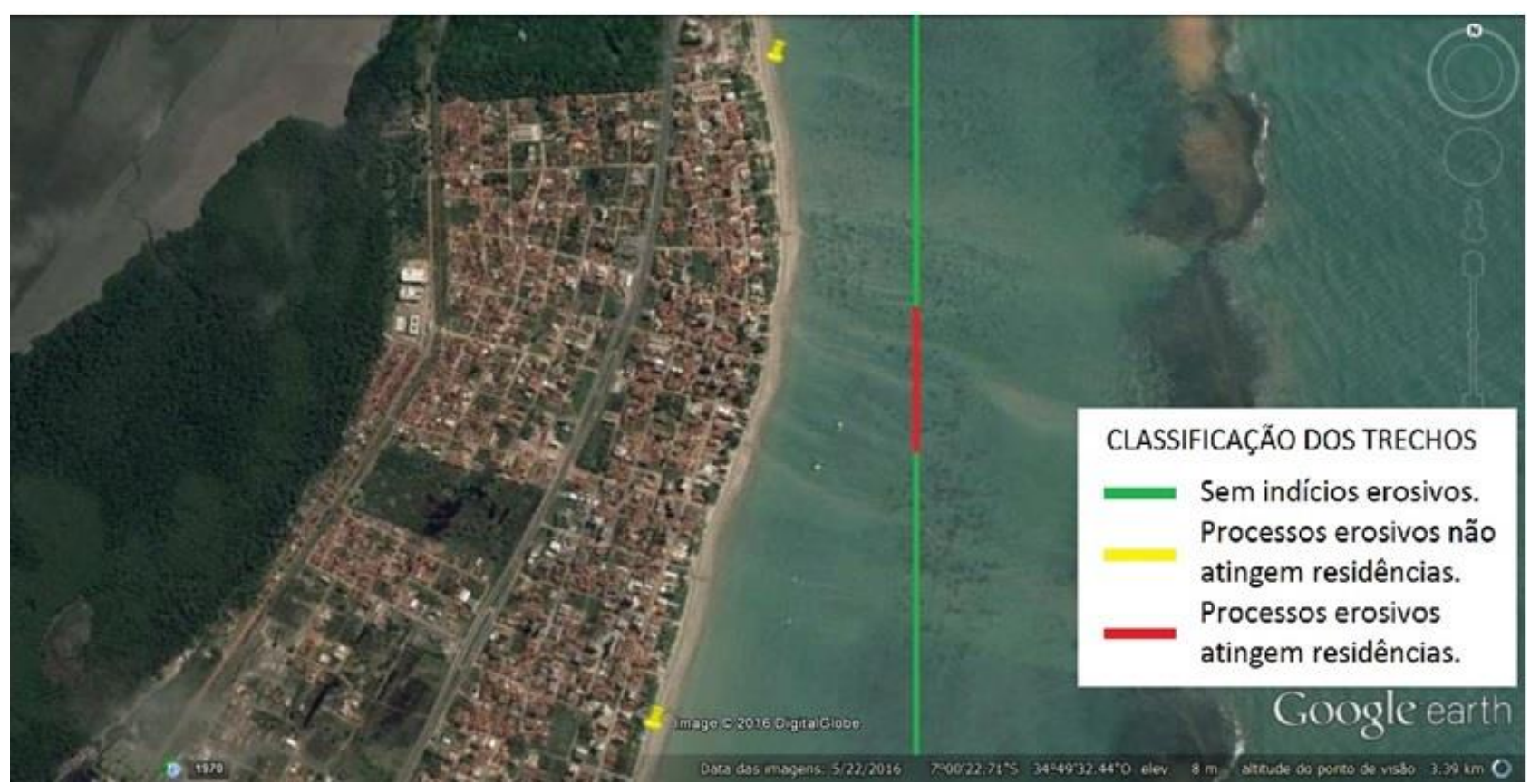

Figura 04: Praia de Camboinha. Fonte: Google Earth. 
Já o setor vermelho representa os locais onde ocorrem os progressos erosivos mais intensos, decorrentes da proximidade dos imóveis que estão localizados metros à frente do que realmente deveriam; fato esse que só ocorre pela falta de fiscalização da SPU (Secretaria do patrimônio da União). A única resposta é da natureza reivindicando o seu espaço derrubando os muros como podemos observar na Figura 05 - B. As residências nesta área possuem sistemas de contenção, como muros de arrimo, telas com rochas; entretanto, com o tempo as estruturas vão cedendo, trazendo mais uma vez o problema aos imóveis.
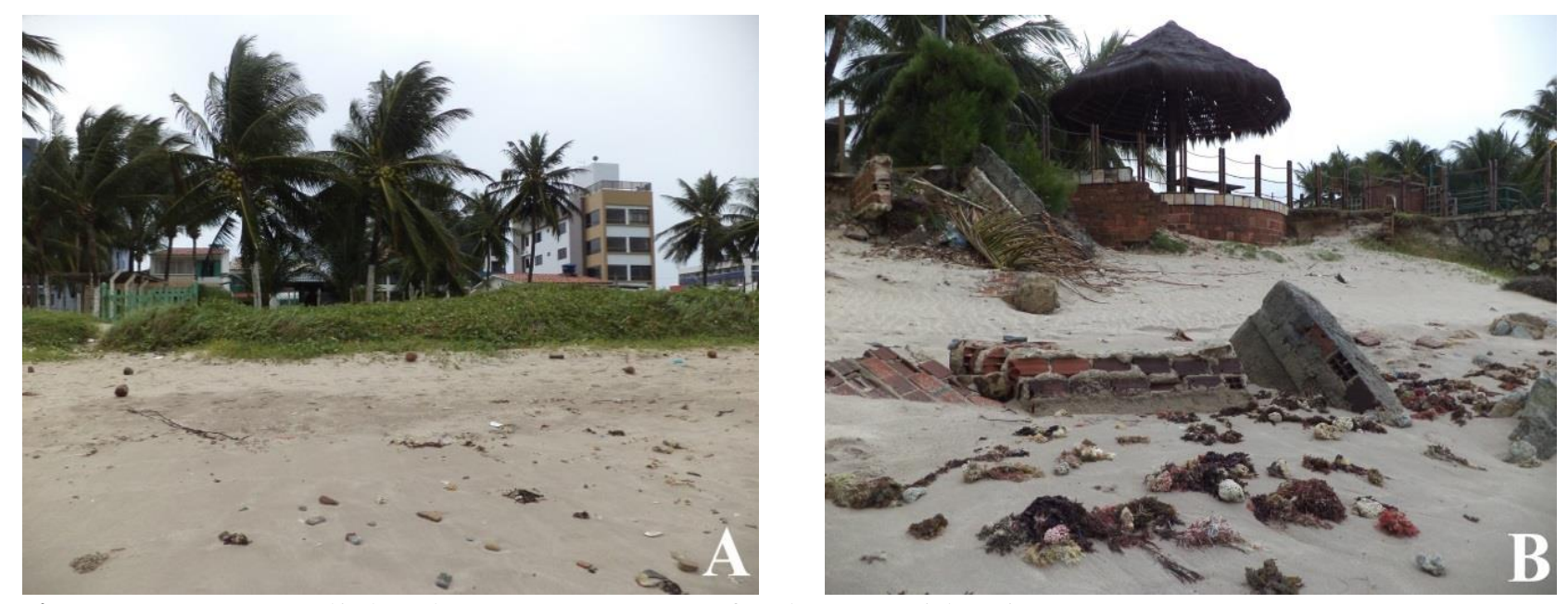

Figura 05: A - A linha de vegetação e ao fundo as residências sem avanço (Sem erosão); B Estruturas de contenção e parte de um terreno destruído. Fonte: Autor, Julho de 2016.

\section{CONSIDERAÇÕES FINAIS}

Diante do que foi exposto, fica evidente que ambas as praias apresentam índice erosivo. $\mathrm{O}$ contraste entre elas está no fato de a praia do Poço apresentar, predominantemente, uma forte erosão costeira decorrente do avanço indevido de vários bares e residências em direção ao mar; enquanto a praia de Camboinha apresenta um equilíbrio proporcionado pelo respeito aos seus limites e pela preservação de sua vegetação, tendo, portanto, apenas um pequeno trecho afetado por forte erosão costeira também decorrente do avanço de imóveis além do limite permitido.

Em outro trabalho que teve vigência no ano 2013/2014 ocorreu o acompanhamento da situação das praias de Poço e Camboinha, e desde aquela época a Secretaria de Patrimônio da União (SPU) já vinha fazendo um trabalho de fiscalização para notificar os imóveis situados em terrenos acrescidos ilegalmente, com o intuito de demoli-los. De fato, no ano de 2014, a Prefeitura do município de Cabedelo, juntamente com a SPU, executou a demolição de alguns bares que não possuíam sequer registro de funcionamento; entretanto, permanecem incólumes as residências. Acontece que o processo de desocupação tramita de forma lenta, devido aos inúmeros recursos 
pedidos pelos moradores e também devido ao emprego da "politica da camaradagem", já que grande parte dessas residências constitui patrimônio de pessoas influentes na sociedade local. O problema da erosão costeira nessas praias existe e é visível para todos; apesar disso, os órgãos responsáveis pela fiscalização prometem medidas de solução rápida, mas não demonstram êxito, o que leva as pessoas a crerem que essas ações de recuperação do ambiente praial passarão por grande demora até que sejam executadas.

A maioria dos imóveis, sejam eles bares ou residências que estão no setor de maior risco, tendem a sofrer com mais problemas com o decorrer dos anos, pois as estruturas de contenção que foram feitas não são adequadas, pois não foram projetadas por um profissional habilitado, além do mais, não passam por nenhum tipo de manutenção, o que ocasiona sua rápida destruição, que culmina em um amontoamento de entulhos em um ambiente que possui um grande potencial turístico natural, que por si só requer sua preservação para utilização sustentável dos seus espaços.

Recomenda-se que se faça um monitoramento sistemático, nas praias estudadas, a fim de que se obtenham dados consecutivos por um período de tempo maior, para que se faça possível à aplicação de técnicas e medidas destinadas a prevenir impactos negativos ou reduzir sua magnitude nestas áreas, bem como um gerenciamento costeiro para tal.

\section{REFERÊNCIAS}

GUERRA, a J. T. CUNHA, S. B.. Geomorfologia: uma atualização de bases e conceitos. $10^{\circ}$ ed. Rio de Janeiro: Editora Bertrand Brasil, 2011.

REIS, C. M. M.. Litoral de João Pessoa (PB) Frente ao Problema da Erosão Costeira. Tese de doutorado apresentado ao Programa de Pós Graduação em Geociências da Universidade Federal de Pernambuco, UFPE, Recife - PE, 2008.

PEDRUZZI, C. V.. Perfil Praial de Equilíbrio da Praia de Camburi. Vitória - ES. Monografia de Graduação apresentado ao Departamento de Ecologia e Recursos Naturais da Universidade Federal do Espírito Santo, UFES, Vitoria - ES, 2005.

SCUDELARI, C.. O uso de check-list como ferramenta de identificação dos processos erosivos na praia da Pipa - RN. $2^{\circ}$ Congresso Brasileiro de Engenharia Sanitária e Ambiental. Campo Grande - MS, 2005.

FALCÃO, S. M.. Evolução da paisagem na orla marítima de Cabedelo em decorrência da dinâmica de ocupação da área e dos conflitos de uso. Dissertação de mestrado apresentado ao Programa de Pós Graduação em Geociências da Universidade Federal da Paraíba, UFPB, João Pessoa - PB, 2004.

SUGUIO, K.. A Importância da Geomorfologia em Geociências e Áreas Afins. Revista Brasileira de Geomorfologia. v. 1, n. 1, p. 80-87, São Paulo, 2000. 
SUPERINTENDÊNCIA DE ADMINITRAÇÃO DO MEIO AMBIENTE-PB, Plano de Gestão Ambiental do Município de Cabedelo. $1^{\circ}$ ed. SUDEMA: GERCO, 1996.

FEITOSA, A.C.. Dinâmica dos processos geomorfológicos da área a nordeste da ilha do Maranhão. Tese de doutorado apresentado ao Programa de Pós Graduação em Geociências e Ciências Exatas, UNESP, Rio Claro - SP, 1996.

CASTRO, J.W. de A.; VALENTINI, E.; ROSMAN, P.C.C.. Estudo diagnóstico do Comportamento Atual da Linha de Costa entre os Rios Pacoti e Tabuba, CE. 37 ${ }^{\circ}$ Congresso Brasileiro de Geologia. Boletim de resumos expandidos, v.1. Simpósios, 1992, p. 27. São Paulo, 1992.

\section{AGRADECIMENTOS}

Agradeço imensamente à Prof ${ }^{\mathrm{a}}$. Dr. Camila Cunico, pelo suporte, pelas suas correções e incentivos.

À minha noiva Joyce pelo paciente trabalho de revisão da redação e apoio moral para o desenvolvimento deste trabalho.

Aos meus amigos André Victor e Tatiana Silva, pela força, compreensão e apoio constante nesse período de aperfeiçoamento do meu trabalho.

Agradeço a Deus por mais esse passo na minha vida.

Recebido em: 14/08/2016

Aceito para publicação em: 01/10/2016 